\title{
EVACUATION ROUTING ASSESSMENT DURING EARTHQUAKE OCCURRENCE IN BUTUAN CITY USING GIS TECHNIQUES
}

\author{
A. G. Cauba Jra , S. N. Ignacio ${ }^{a}$ \\ ${ }^{a}$ Department of Geodetic Engineering, College of Engineering and Geosciences, \\ Caraga State University, Ampayon, Butuan City, Philippines - agcauba@ carsu.edu.ph
}

KEY WORDS: Analytical Hierarchy Process (AHP), Earthquakes, Evacuation Routes, Road Networks, Vulnerability Assessment

\begin{abstract}
:
Butuan City lies along and is being transected by the Philippine Fault: Surigao Segment. As earthquakes occur more recently, the city is more vulnerable to earthquake hazards, especially soil liquefaction. With the city proper situated mostly on areas susceptible to soil liquefaction and with no constructive evacuation plan against this kind of hazard, it puts the city at risk. This problem highlights the importance of vulnerability assessment for the identification of the road networks that would be most optimal to use in occurrence of an earthquake and an earthquake induced liquefaction. With seven parameters to consider for the assessment, it would be easier to assess by using the pairwise comparison technique of the Analytical Hierarchy Process (AHP) and Geographic Information System (GIS). The analysis was performed by using AHP to assign weights to the parameters and using these weights to classify the road networks into vulnerability classes. The result of the analysis yielded to $34.87 \%$ of the road networks with low vulnerability, $65.09 \%$ has medium vulnerability and $0.03 \%$ are considered to be highly vulnerable. Majority of the road networks especially in the city proper exhibit medium vulnerability in terms of earthquake occurrences. With unavoidable chances that this kind of disaster would happen, these results would benefit the decision makers involved in disaster risk reduction.
\end{abstract}

\section{INRODUCTION}

Eastern Mindanao is one of the seismically active areas in the Philippines because of the Philippine Fault and Philippine Trench, which are the main earthquake generators that can affect the area. Butuan City lies along and is being transected by the Philippine Fault: Surigao Segment making it vulnerable to seismic hazards. At present, given that earthquake prediction is still not attainable, it heightens the risk of the occurrence of seismic hazards throughout the country (Tupaz, V., 2017). After a strong earthquake, some buildings and infrastructures may possibly fall, blocking off roads and streets, thus making roads not accessible for evacuation purposes. In other words, roads and paths trapped between demolished buildings play a key role in the aftermath of the earthquake (Rastegar, A., 2017).

In this paper, the authors employed an AHP Pairwise Comparison as a decision-making tool and also used a GIS-based Weighted Overlay Analysis to generate a vulnerability map. These techniques were implemented to assess the road networks in Butuan City and its accessibility in an occurrence of an earthquake. Butuan City is a highly urbanized city and the regional center of the Caraga Region, Mindanao, Philippines (Wikipedia, 2019). It has an area range of 81,662 hectares or $816.62 \mathrm{~km}^{2}$ which is subdivided into 86 barangays and grouped into 13 districts. Its current population is 337,063 according to the 2015 Census of Population (Philippine Statistics Authority, 2015). Given that city is transecting along a fault line making it more vulnerable to earthquake occurrences, while its city proper and low-lying barangays situated mostly on sandy sediments, it makes the city more vulnerable to liquefaction during an earthquake.

Hence, this study is concerned on which road networks of the city can still be accessible and can be used as an evacuation route after the occurrence of an earthquake and an earthquake induced liquefaction alongside with some parameters affecting an

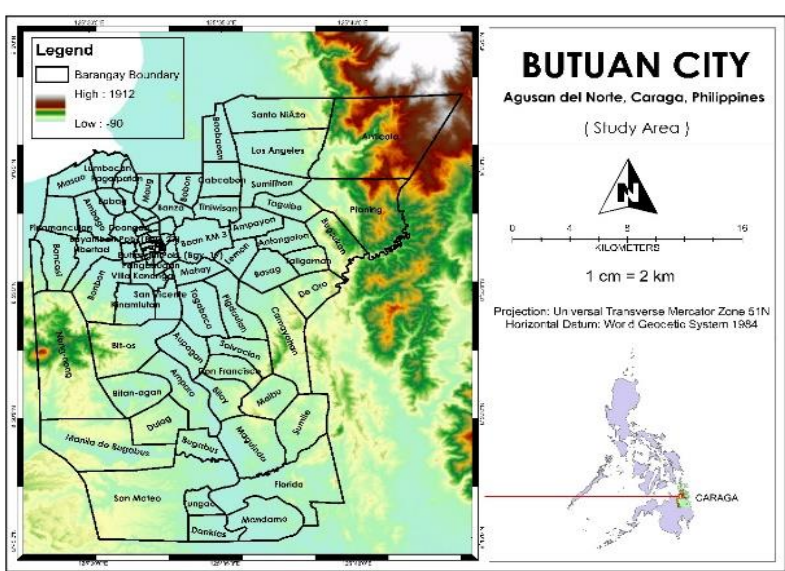

Figure 1. Study Area

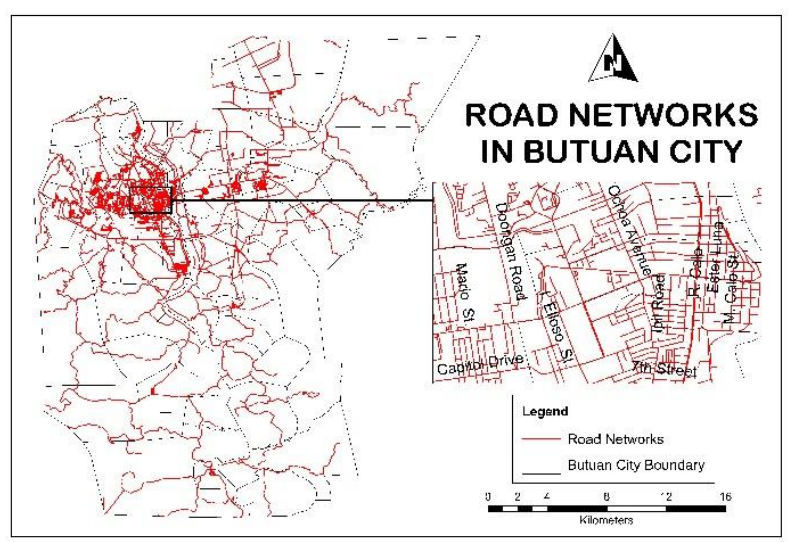

Figure 2. Road Networks Map evacuation route. 


\section{METHODOLOGY}

The methodology consists of four (4) major activities namely; establishing criteria and reclassification of values for each criterion, AHP for weight generation, weighted overlay analysis, and road network vulnerability assessment. The vulnerability map was produced in order to locate the road networks that can be used as an evacuation route.

\subsection{Establishing criteria and Reclassification of values for each criterion}

When doing an assessment of road network evacuation, the authors studied the spatial structure of the street network and identified the areas that are generally used for evacuation. To assign vulnerabilities, the authors identified seven (7) parameters to aid the assessment which can be seen in Table 1 . Reclassification was done to allow easy changes in vulnerability to a new and specified value. This study made use of 3 specified values namely, 1 for Low Vulnerability, 2 for Medium Vulnerability, and 3 for High Vulnerability.

\begin{tabular}{|c|c|c|c|}
\hline Criteria & $\begin{array}{c}\text { Standard } \\
\text { adopted }\end{array}$ & Vulnerability & $\begin{array}{c}\text { New } \\
\text { values }\end{array}$ \\
\hline \multirow{3}{*}{$\begin{array}{l}\text { Building } \\
\text { Density }\end{array}$} & $\begin{array}{l}0-20 \text { per } \\
\text { hectare }\end{array}$ & Low & 1 \\
\hline & $\begin{array}{l}\text { 21-51 per } \\
\text { hectare }\end{array}$ & Medium & 2 \\
\hline & $\begin{array}{l}\text { More than } \\
51 \text { per } \\
\text { hectare }\end{array}$ & High & 3 \\
\hline \multirow{3}{*}{$\begin{array}{l}\text { Building } \\
\text { Quality }\end{array}$} & $\begin{array}{c}\text { New or } \\
\text { Renovated }\end{array}$ & Low & 1 \\
\hline & $\begin{array}{l}\text { Maintained } \\
\text { or Existing }\end{array}$ & Medium & 2 \\
\hline & $\begin{array}{c}\text { On-going } \\
\text { construction }\end{array}$ & High & 3 \\
\hline \multirow{4}{*}{$\begin{array}{l}\text { Peak Ground } \\
\text { Acceleration }\end{array}$} & $<0.10 \mathrm{~g}$ & Low & 1 \\
\hline & $0.10-0.25 \mathrm{~g}$ & Medium & 2 \\
\hline & $\begin{array}{l}\text { more than } \\
0.25 \mathrm{~g} \text { ( but } \\
\text { no active } \\
\text { fault line } \\
\text { within } 10 \mathrm{~km} \\
\text { of site) }\end{array}$ & \multirow[t]{2}{*}{ High } & \multirow[t]{2}{*}{3} \\
\hline & $\begin{array}{l}\text { More than } \\
0.25 \mathrm{~g} \mathrm{(} \\
\text { active fault } \\
\text { closer than } \\
10 \mathrm{~km} \text { from } \\
\text { site) }\end{array}$ & & \\
\hline \multirow{3}{*}{$\begin{array}{l}\text { Population } \\
\text { Density }\end{array}$} & $\begin{array}{l}\text { Up to } 750 \\
\text { per } k^{2}\end{array}$ & Low & 1 \\
\hline & $\begin{array}{c}751-2298 \\
\mathrm{~km}^{2}\end{array}$ & Medium & 2 \\
\hline & $\begin{array}{c}\text { More than } \\
2299 \text { per } \\
\mathrm{km}^{2} \\
\end{array}$ & High & 3 \\
\hline \multirow{2}{*}{$\begin{array}{l}\text { Proximity to } \\
\text { an active } \\
\text { fault line }\end{array}$} & Up to $5 \mathrm{~m}$ & High & 3 \\
\hline & $\begin{array}{c}\text { More than } 5 \\
\mathrm{~m}\end{array}$ & Low & 1 \\
\hline \multirow{3}{*}{$\begin{array}{l}\text { Proximity to } \\
\text { medical } \\
\text { center }\end{array}$} & $\mathrm{Up}$ to $100 \mathrm{~m}$ & Low & 1 \\
\hline & $101-500 \mathrm{~m}$ & Medium & 2 \\
\hline & $\begin{array}{l}\text { More than } \\
501 \mathrm{~m}\end{array}$ & High & 3 \\
\hline
\end{tabular}

\begin{tabular}{|c|c|c|c|}
\hline $\begin{array}{c}\text { Susceptibility } \\
\text { to Soil } \\
\text { Liquefaction }\end{array}$ & $\begin{array}{c}\text { Not } \\
\text { Susceptible }\end{array}$ & Low & 1 \\
\cline { 2 - 4 } & Susceptible & High & 3 \\
\hline
\end{tabular}

Table 1. Reclassified Values

\subsection{AHP for Weight Generation}

To make decisions, Saaty made use of a scale of numbers that indicates how many times more important or dominant an element is as to another element with respect to the criterion in which they are being compared. This technique is called the Pairwise Comparison and will result to the weight of each criterion (Saaty, T., 20008).

To determine the weight, the authors first calculated the nth root as shown in equation 1 . The nth root will be used as shown in equation 2 to produce the Eigenvector or also called Priority Vector. This will now represent the individual weight of each criterion.

$$
\text { Nth root }=\left(X_{1} * X_{2} * X_{3} \ldots * X_{n}\right)^{1 / n}
$$

where $\quad \mathrm{X}=$ Rating of expert in pairwise comparison $\mathrm{n}=$ Number of Indicator

$$
\text { Eigenvector }=\frac{\text { Nthroot }}{\left.\sum \text { (Nthroot }\right)}
$$

The resulting weight is still not final since consistency is still needed. The consistency referred to is the Consistency Ratio. This represents the consistency of the judgement of the experts on their decisions. This was calculated using the value of consistency index as shown in equation 3. The Consistency Ratio was then calculated using equation 4. RI or Random Index was derived from Table 2, where $\mathrm{N}$ represents the number of parameters, criteria or indicators involved in the study.

$$
C I=\frac{(\lambda-n)}{(n-1)}
$$

where $\quad \mathrm{CI}=$ Consistency Index

$\lambda=$ Lambda max; derived from the summation of products between each criteria eigenvector and the sum of each respective column on the matrix $\mathrm{n}=$ Number of Indicato

$$
C R=\frac{C I}{R I}
$$

where $\quad \mathrm{CR}=$ Consistency Ratio

$\mathrm{CI}=$ Consistency Index

$\mathrm{RI}=$ Random Index

\begin{tabular}{|c|c|c|c|c|c|c|c|c|c|c|}
\hline $\mathrm{N}$ & 1 & 2 & 3 & 4 & 5 & 6 & 7 & 8 & 9 & 10 \\
\hline $\mathrm{RI}$ & 0 & 0 & 0. & 0. & 1. & 1. & 1. & 1. & 1. & 1. \\
\hline
\end{tabular}

Table 2. Random Consistency Indices (RI) for N=10

\subsection{Weighted Overlay Analysis}

To assign vulnerability to road networks, the authors used weighted overlay analysis tool. Table 3 shows the calculations done in the said tool in order to produce the vulnerability map. This is to visualize the portions in the city where roads are classified into low, medium and high vulnerability. The map was then overlaid with the road network and thus resulting to the final 
output map, which can be used to derive the optimal evacuation route.

\begin{tabular}{|c|}
\hline $\begin{array}{c}\text { (Reclassified Building Density Map) X (AHP weight of } \\
\text { Building Density) }\end{array}$ \\
\hline+ \\
\hline $\begin{array}{c}\text { (Reclassified Building Quality Map) X (AHP weight of } \\
\text { Building Quality) }\end{array}$ \\
\hline+ \\
\hline (Reclassified PGA Map) X (AHP weight of PGA) \\
\hline+ \\
\hline $\begin{array}{c}\text { (Reclassified Population Density Map) X (AHP weight of } \\
\text { Population Density) }\end{array}$ \\
\hline+ \\
\hline $\begin{array}{l}\text { (Reclassified Proximity to Active Fault line Map) X (AHP } \\
\text { weight of Proximity to Active Fault line) }\end{array}$ \\
\hline+ \\
\hline $\begin{array}{c}\text { (Reclassified Proximity to Medical Centers Map) X (AHP } \\
\text { weight of Proximity to Medical Centers) }\end{array}$ \\
\hline+ \\
\hline $\begin{array}{c}\text { (Reclassified Soil Liquefaction Map) X (AHP weight of } \\
\text { Soil Liquefaction) }\end{array}$ \\
\hline$=$ \\
\hline Vulnerability Map \\
\hline
\end{tabular}

\subsection{Road Network Vulnerability Assessment}

After the vulnerability map is generated, it was overlaid with the road network shapefile. This resulted to the road networks having an assigned vulnerability. The final output generated after this was the optimal evacuation routes to be taken in the occurrence of an earthquake.

The output was then categorized by their vulnerability by presenting a map. Roads were categorized by vulnerability by color; red for the high vulnerability, yellow for the medium vulnerability, and green for the low vulnerability. In this case, the road network to be considered during evacuation should be the least vulnerable, hence, the low vulnerable roads.

\section{RESULTS AND DISCUSSIONS}

\subsection{Generated Weights from AHP}

Given that the study established seven different parameters to put into consideration when deciding an evacuation route, these parameters were evaluated by five (5) experts using the AHP Pairwise Comparison, in order to assign weights. Individual weights of the experts were then averaged to come up with the final individual weight of the seven parameters as shown in Table 4.

\begin{tabular}{|c|c|c|}
\hline Criteria & $\begin{array}{c}\text { Average } \\
\text { Eigenvector } \\
\text { (Priority Vector) }\end{array}$ & $\begin{array}{c}\text { Average Final } \\
\text { Weight }\end{array}$ \\
\hline Building Density & 0.073196744 & $7.32 \%$ \\
\hline Building Quality & 0.168590113 & $16.86 \%$ \\
\hline $\begin{array}{c}\text { Peak Ground } \\
\text { Acceleration }\end{array}$ & 0.070081625 & $7.01 \%$ \\
\hline Population Density & 0.171386283 & $17.14 \%$ \\
\hline $\begin{array}{c}\text { Proximity to } \\
\text { Active Fault }\end{array}$ & 0.182154323 & $18.22 \%$ \\
\hline $\begin{array}{c}\text { Proximity to } \\
\text { Medical Center }\end{array}$ & 0.161676532 & $16.17 \%$ \\
\hline
\end{tabular}

\begin{tabular}{|c|c|c|}
\hline Soil Liquefaction & 0.17291438 & $17.29 \%$ \\
\hline Table 4. Final individual weight of criterion
\end{tabular}

Shown in Table 4, the highest weight among all the seven parameters is the Proximity to Active Fault. With this, it can be concluded that the decision of the five (5) experts in choosing the most optimal evacuation route should consider the roads proximity to an active fault line as the highest priority. This is to be followed by the susceptibility of Soil Liquefaction. Then Population Density, Building Quality, Proximity to Medical Centers, Building Density and lastly, the Peak Ground Acceleration.

\subsection{Vulnerability Hazard Maps}

The generated vulnerability map using Weighted Overlay Assessment is shown in Figure 3. This map shows the portions of Butuan City where vulnerabilities are depicted.

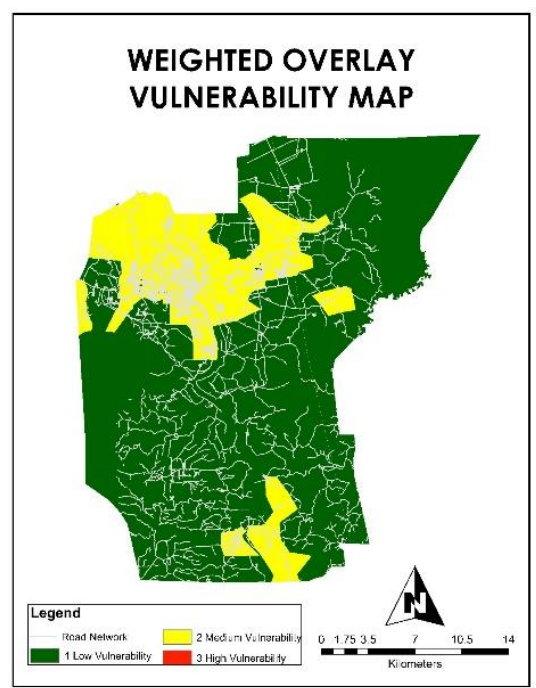

Figure 3. Weighted Overlay vulnerability Map of Butuan City

3.2.1 Roads with low vulnerability: This study focuses on finding an optimal road network in an event of an earthquake and earthquake induced landslide by identifying the road networks with the lowest vulnerability. Figure 4 exhibits the road networks with the lowest vulnerability considering the seven parameters, making these roads the most optimal network when planning an evacuation route since these roads provide the biggest movement throughout the city.

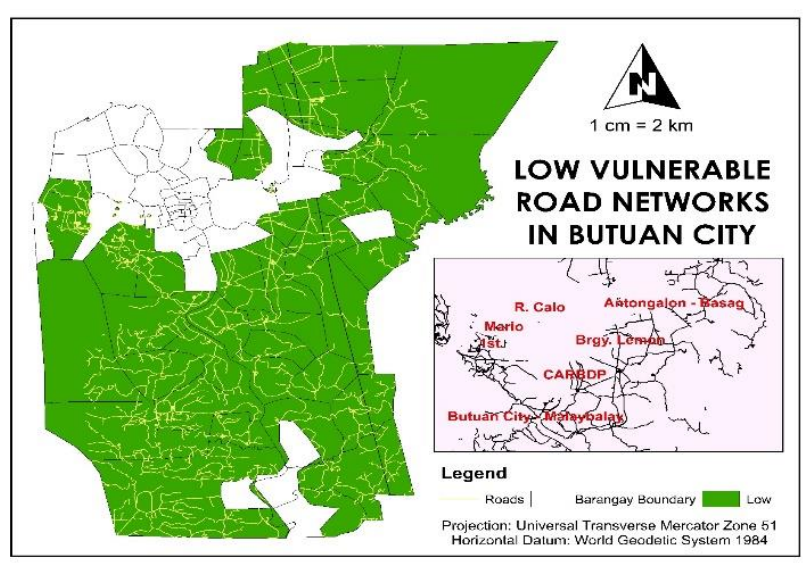

Figure 4. Low vulnerable road networks. 
3.2.2 Roads with medium vulnerability: Shown in Figure 5, the portion which are generally classified to have medium vulnerability are the roads in the city proper. These roads mostly exhibit susceptibility to soil liquefaction and the city proper, among all the areas in Butuan City, accommodates the most buildings. In other words, it has a possibility of road blockage caused by toppled buildings. This reason alone can jeopardize the flow of the rescue operation and could possibly cause chaos in times of a disaster.

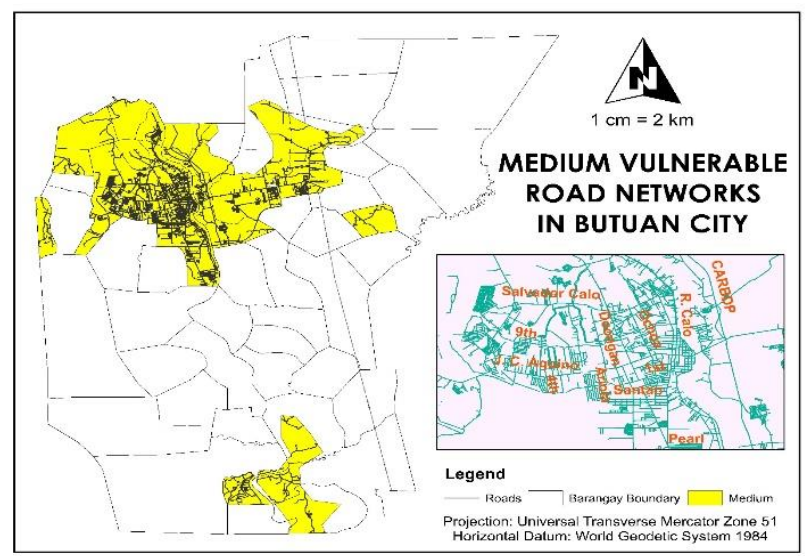

Figure 5. Medium vulnerable road networks.

\subsubsection{Road with high vulnerability:}

This is not

clearly visible in the vulnerability map, but there is a small portion where there is high vulnerability. The road is located besides an on-going construction of a hotel. It is a small juncture of road connected with an avenue.

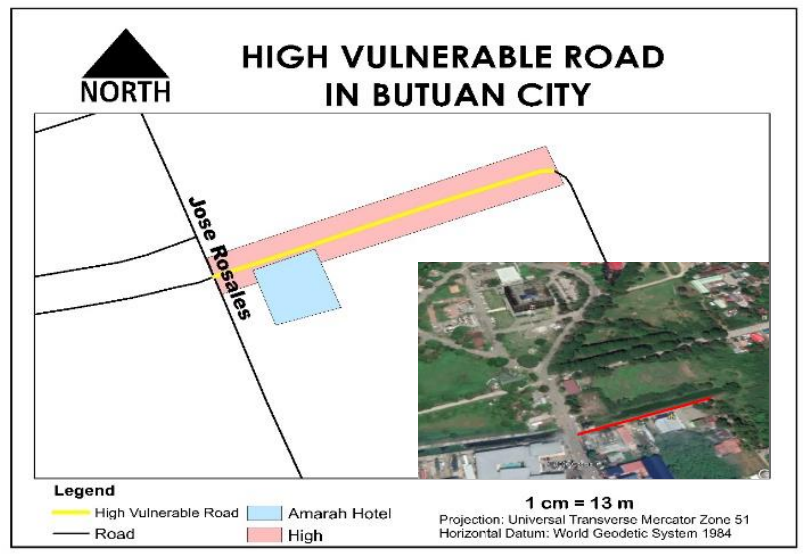

Figure 6. Highly vulnerable road network.

After assigning vulnerability, road networks were broken down into; 1,182 low vulnerable roads, 2,206 medium vulnerable roads and 1 highly vulnerable road. Respectively, $34.87 \%$ of the roads are classified as low, $65.09 \%$ as medium and $0.03 \%$ of the total number of roads are considered as high. With these results, $34.87 \%$ of the road networks are considered to be safe and optimal when planning an evacuation route. In contrast to this, majority of the road networks in the city have medium vulnerability. These roads are mostly situated on soil liquefaction susceptible areas. This is important to know because when it comes to planning an evacuation route, the responders need to be aware of possible hazards that may come in order to execute a successful response.

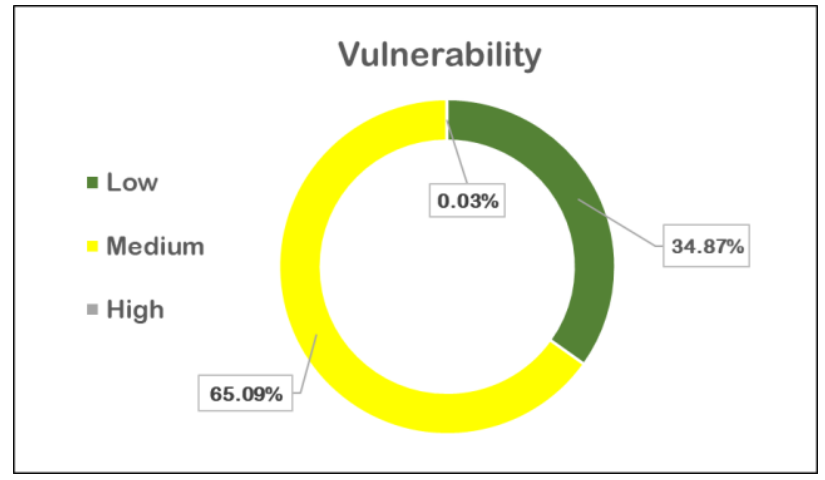

Figure 7. Road network vulnerability by percentage.

\section{CONCLUSIONS AND RECOMMENDATIONS}

The study shows the systematic process to assess the road networks in order to produce the optimal evacuation route in the events of an earthquake in Butuan City. The AHP Pairwise Comparison and Weighted Overlay Analysis, in which the road network feature was overlaid in the vulnerability map, were utilized. The final vulnerability map allowed the generation of three (3) road network vulnerability maps that correspond to the low vulnerable roads, medium vulnerable roads and highly vulnerable road. The results show that $34.87 \%$ of the total road networks in the city are considered safe and can be utilized as an optimal evacuation route. The results of this study can be a contribution to the Local Government Unit of Butuan City which are dedicated to the disaster risk reduction in the city. This can also benefit the general population of the city in order to provide knowledge on where might be the safest roads to take.

Although the study focuses on the impacts of an earthquake occurrence, it is also important to take note that only one seismic activity was included, soil liquefaction. In order to make a more in-depth research, all five (5) identified seismic activities should be considered. namely, earthquake-induced landslide, earthquake-induced tsunami, ground rupture, ground shaking and soil liquefaction. Also, incorporating more parameters other than the those used in the assessment, like the flow of traffic in a certain route could also be considered.

\section{ACKNOWLEDGEMENT}

The authors would like to express their gratitude to PHIVOLCS Surigao, CCGeo, BCMFC, OBO, CDRRMO and the OCD for providing the needed datasets and extending their expertise during the conduct of the study. The authors would also like to extend thanks to their colleagues and families for the much needed support. To God be the glory.

\section{REFERENCES}

Philippine Statistics Authority, 2015. 2015 Census of Population Region-XIII CARAGA. Ref. No. 2016-078. psa.gov.ph/content/population-region-xiii-caraga-based-2015census-population.

Rastegar, A., 2017. Assessing Urban Streets Network Vulnerability against Earthquake Using GIS - Case Study: $6^{\text {th }}$ Zone Of Tehran. The International Archives of the Photogrammetry, Remote Sensing and Spatial Information

Sciences. XLII-4/W4, 455-462, https://doi.org/10.5194/isprsarchives-XLII-4-W4-455-2017, 2017. 
Saaty, T., 2008. Decision making with Analytic Hierarchy Process. International Journal of Services Sciences. Vol. 1 No. 1, pp.83-98. https://doi.org/10.1504/IJSSCI.2008.017590.

Tupaz, V., 2017. PHIVOLCS explains strong Surigao quake. Rappler. https://www.rappler.com/moveph/watch-phivolcsexplains-strong-surigao-quake-february-2017. Retrieved 18 May 2019.

Wikipedia. Butuan. https://en.wikipedia.org/wiki/Butuan. Retrieved 18 May 2019. 